\title{
Adapting the Asset Exercise for humanitarian contexts
}

Women's Refugee Commission

Population Council

Follow this and additional works at: https://knowledgecommons.popcouncil.org/departments_sbsr-pgy

Part of the Family, Life Course, and Society Commons, Health Communication Commons, International Public Health Commons, and the Women's Health Commons How does access to this work benefit you? Let us know!

\section{Recommended Citation}

Women's Refugee Commission and Population Council. 2020. "Adapting the asset exercise for humanitarian contexts," brief. New York: Population Council. 


\section{ADAPTING THE ASSET EXERCISE FOR HUMANITARIAN CONTEXTS}

\section{INTRODUCTION}

\section{Action learning and practical tools for humanitarian contexts}

As part of our long-standing partnership to promote evidence-based approaches to programming with and for adolescent girls affected by emergencies, the Women's Refugee Commission (WRC) and the Population Council conducted a joint project to adapt the Building Assets Toolkit (https://www.popcouncil.org/research/building-assets-toolkit-developing-positive-benchmarks-for-adolescent-girls) and its core activity, the "Asset Exercise," to serve girls and inform program design in humanitarian contexts. We conducted key informant interviews with 12 professionals who had participated in and facilitated the Asset Exercise across diverse regions and forms of emergency, including conflict, natural disaster, and infectious disease outbreaks. We also drew on observations and reports from field activities conducted as a standalone exercise, or as part of WRC's “I'm Here" approach (Robles 2016).

Our interviews and report reviews sought to answer two guiding questions:

1. How, and with whom, has the Asset Exercise been used?

2. When during humanitarian operations/at what stages in response has the Asset Exercise been used?

In addition, we asked interview participants to provide feedback and offer concrete examples of adaptations to the Asset Exercise, and accompanying guidance that would best achieve our shared commitment to supporting the design and delivery of high-quality girl-centered programming.
While this document reflects learning from humanitarian contexts, the insights and adaptations may be relevant to girl-centered program design and capacity strengthening across the diverse settings where "asset-building" programs for girls are implemented.

\section{ASSET-BUILDING AND THE ASSET EXERCISE}

As a guiding program theory, asset-building centers on the idea that skills, knowledge, relationships, and concrete resources can all constitute assets, or "stores of value," that girls can, in turn, mobilize to make healthy choices, seek support, navigate institutions, and access entitlements. This approach is inherently multisectoral, rooted in a commitment to prioritize understanding of and respond to the diversity of girls' needs, capacities, and experiences (Temin et al. 2018).

The Asset Exercise is an activity that operationalizes the concept of "asset-building" into concrete terms. The exercise consists of a deck of 100 "asset cards," and eight "age cards" (at 2-year intervals for ages 6-20). Asset cards reflect both intrinsic qualities (such as self-confidence), concrete knowledge (such as awareness of legal entitlements), and practical skills (such as the ability to fill out a form). During the activity, participants work as a group to review cards, and, working as a group, decide at which age girls should possess specific assets. The activity may be used in various settings and with groups such as development or humanitarian professionals, or in community settings with adolescent girls or their mothers or fathers. The Asset Exercise may be used to:

- Provoke critical thinking among practitioners about program goals and content interventions intended to support girls in general;

The Population Council conducts research and delivers solutions that

It's our model for global change. popcouncil.org 
- Engage girls, practitioners, and community stakeholders in the same process, and gather perspectives on what adolescent development should entail; and

- Inform decision-making about program design, such as refining program content appropriate for those groups, linking programming across sectors, or defining program indicators.

As part of the Building Assets Toolkit, the Asset Exercise is accompanied by an instruction guide outlining the evidence behind each asset and a set of worksheets intended to guide practitioners in developing program content or defining indicators of programs' effects on knowledge or skills acquisition.

\section{RESULTS FROM GUIDING QUESTION 1: HOW AND WITH WHOM HAS THE ASSET EXERCISE BEEN USED?}

The practitioners we interviewed reported that the Asset Exercise was most often used with program staff, typically during regional or national workshops, to strengthen institutional capacity to better respond to adolescent girls' age and gender-specific experiences and distinct needs, rather than to inform programspecific design decisions. In these workshop contexts, the exercise:

1. Fosters collective reflection and enables participants to question assumptions about the function of existing program approaches and the potential value of girl-specific programming;

2. Provides a lens for practitioners to assess whether existing program curricula for girls' programming is age-appropriate and incorporates content and learning strategies to support girls in building relevant assets;

3. Promotes critical thinking about the cross-sector coordination necessary to ensure that girls build the diverse assets they need to safely navigate transitions from childhood through adolescence and into early adulthood.

Overall, interviewees reported that they found participation in the Asset Exercise has often served to shift staff members' perspectives from a view that focuses on simply carrying out activities, to a girl-centered perspective-thinking first about what girls need, and questioning their assumptions about what programs are doing. This has prepared them to assess what programs: (a) are currently delivering; (b) could improve with immediate modifications; and (c) could accomplish if guided by a commitment to asset-building and intentional design steps.

In one example, an interviewee explained that the exercise prompted practitioners to rethink the assumption that "safe spaces are just a place for girls to play," and to recognize their importance in providing a reliable meeting place, allowing girls to build routines and relationships.

Very few programs have incorporated use of the Asset Exercise with girls, mentors, or caregivers. Interviewees reported that while they believed that the Asset Exercise holds promise for use with these groups, its current structure required substantial adaptation for use with community members. For example, preparing the exercise for a given social context and participant group requires careful attention to sorting and selecting cards, ideally by a gender-based violence or child-protection specialist who has experience working in the specific context. In the absence of such expertise, facilitators may be overly cautious, eliminating "sensitive" topics, such as sexual and reproductive health, thereby missing a valuable learning opportunity. In addition, facilitators may simply skip cards that include complex concepts if it seems too difficult to quickly identify, explain, or translate their main ideas.

\section{CASE STUDY: WEST AFRICA EBOLA RESPONSE}

One practitioner used the Asset Exercise in participatory consultations with girls and caregivers. First, she led the exercise with a small group of local young female staff members. That group then selected, translated, and simplified asset cards and acted as facilitators. They convened groups of 10 participants each: girls ages 10-14 and 15-19, and adult caretakers.

Girls grouped assets at earlier ages than facilitators anticipated: often at age 6 or 8 . In discussing their choices, girls described the extreme economic hardship of the Ebola crisis as exacerbating existing forms of exploitation, with adolescent girls facing pressure from men to exchange sex for basic necessities. They reported that 
neither girls nor the adults in their lives were prepared for this, nor equipped to seek safer economic protections. The staff members observed that caregivers' selections skewed toward early adolescence (10-12), illustrating both their concern and limited understanding of the pressures on girls.

Findings from the Asset Exercise informed the selection of topics for program content to be used with newly formed girls' groups.

\section{RESULTS FROM GUIDING QUESTION 2: WHEN DURING HUMANITARIAN OPERATIONS HAVE PRACTITIONERS USED THE ASSET EXERCISE?}

Practitioners reported that the Asset Exercise has most often been used in protracted emergencies or complex emergency contexts, where response may be characterized by high staff turnover and limited resources for girls' programming. These dynamics create an ongoing need to orient staff and infuse key concepts into program priorities. Participants affirmed that the Asset Exercise has been valuable for these purposes. However, several noted that the current guidance outlining "next steps" rests on the assumption that staff have the skills, authority, and time to review and alter program content, which may not hold true. Thus they recommended developing new guidance to encourage practitioners to apply their learning, even if they may not have authority over revisions in program content.

Interviewees confirmed that the Asset Exercise has not been used during the acute phase of an emergency or initial response. They agreed that given that the focus in this phase is delivering basic needs and is governed by existing standards and guidance, such as those produced by the United Nations' Inter-Agency Standing Committee (IASC) and Sphere community, the Asset Exercise may have limited additional value. The same is often true of high migration contexts, where programs have limited contact with individual girls and cannot feasibly "build assets." However, some suggested that while it has not yet been used in Disaster Risk Reduction (DRR), for DRR practitioners, "asset building" may be valuable for prompting considerations of how to prioritize and support girls as emergencies unfold.

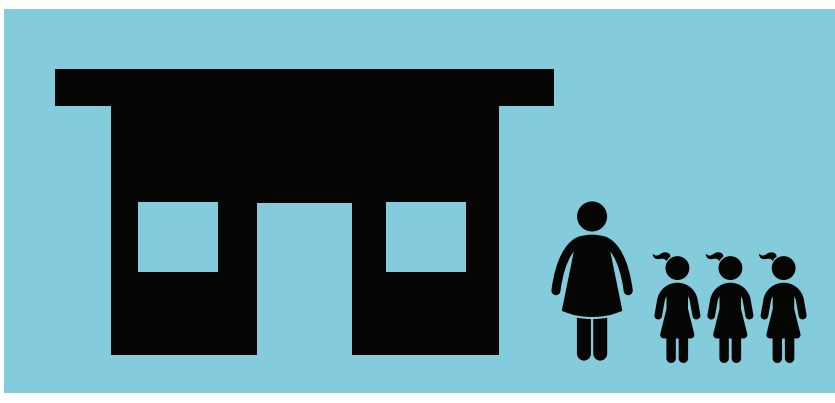

\section{GIRLS' SAFE SPACES IN ACUTE EMERGENCIES}

While many features of the long-term, developmental view of "asset-building" may not be appropriate during the acute stage of an emergency, several practitioners described the value of including designated "safe spaces" in acute stage response, given the routines, and relationships, for adolescent girls even absent other formal learning content. Some further suggested that given existing commitments to establish "child-friendly" and "woman-friendly" spaces, it would be feasible to make adolescent girls' spaces a standard feature of response design.

\section{ADAPTATIONS}

We adapted the Asset Exercise, drawing on a series of recommendations from practitioners. These changes aimed to:

1. Prioritize assets according to their relevance across settings and emergency response stages.

We developed three categories for assets. The first, a core set, are appropriate to any setting. In reviewing the existing list, we sought to limit the number of assets in this category to 30 cards to ensure that most groups would be able to complete a review and discussion of the full set. We organized remaining assets into two categories: those relevant to some policy and social contexts, such as differences in legal age at marriage, and those that assume the presence of sector- or program-specific resources or capacity.

2. Simplify concepts and reduce the number of cards.

We revised the cards to simplify phrasing and ensure that each presented only one concept. To reduce the number of cards, we assessed where the concepts 
from multiple assets appeared redundant, and then either selected one or consolidated to emphasize the simplest overarching idea. We also removed asset cards that presumed a level of infrastructure development, or specific features of resources or institutions that may not be present in humanitarian contexts.

3. Categorize assets according to domains (e.g., health, social, economic).

We introduced a color-coding scheme to organize by domain so that facilitators leading debriefs or interpretation sessions can easily see how participants understand the relationships among assets of different types, and/or whether they prioritize assets from one domain as relevant to younger vs. older girls.

\section{CONCLUSION}

The Asset Exercise most often serves as an introduction to the idea of "asset-building," as an entry-point for humanitarian program staff to think about the purpose or priorities of a community-based program for girls. Overall, we found that the Asset Exercise, as currently structured, is a valuable tool for practitioners to gain or deepen their own understanding of key concepts in girls' programming design and to "think from the perspective of a girl" across contexts and stages in program design and delivery. While few practitioners have used it in community contexts, the activity also holds potential as a participatory design tool. We drew on insights and recommendations from practitioners to develop a set of modifications that will better address the needs in these contexts.

\section{NEXT STEPS}

First, we will continue, through both direct engagement with humanitarian partners and through the Council's Community of Practice for girl-centered programming, to invite practitioners to review, use, and share feedback on further changes and on insights gathered from using the revised Asset Exercise.
In addition, we will pursue two additional steps, pending funding and field-testing opportunities:

1. To determine whether the revised language and priority assigned to cards is relevant to practitioners or the communities we work with, we will seek opportunities to partner with humanitarian practitioners to field-test in both staff workshop and community contexts.

2. We will work to implement two recommendations that emerged as important themes but were not feasible with the funding available for this project:

a. Develop complementary visuals so that the cards are more accessible to low literacy groups, and more easily translated into multiple languages.

b. Introduce specific guidance for practitioners to use in interpreting and using the results of the Asset Exercise in settings such as general capacity strengthening workshops for staff, and participatory design activities with community members.

\section{REFERENCES}

Population Council. 2015. Building Assets Toolkit. New York: Population Council. Retrieved from www.popcouncil.org/research/building-assets-toolkitdeveloping-positive-benchmarks-for-adolescent-girls

Robles, O.J. 2016. I'm Here: Steps \& Tools to Reach Adolescent Girls in Crisis. New York: Women's Refugee Commission. Retrieved from www.womensrefugeecommission.org/populations/ adolescent-girls/research-and-resources/1078-i-m-herereport-final-pdf

Temin, M., S. Amin, T.D.Ngo, and S. Psaki. 2018. "How to give girls voice, choice and control," Stanford Social Innovations Review. Retrieved from https://ssir.org/ articles/entry/how_to_give_adolescent_girls_voice_ choice_and_control\#

Since 2012, the Population Council and Women's Refugee Commission (WRC) have pursued an action learning partnership, centered on developing and refining field tools that can make humanitarian responses more responsive to adolescent girls' needs, risks, and capacities.

WRC is a research and advocacy organization which for three decades has worked to improve the lives and protect the rights of refugee and internally displaced women, children and youth through research, technical assistance, public education and targeted advocacy. womensrefugeecommission.org 